\title{
Work related sexual harassment and risk of suicide and suicide attempts: prospective cohort study
}

\section{Check for updates}

\section{Linda L Magnusson Hanson, ${ }^{1}$ Anna Nyberg, ${ }^{1}$ Ellenor Mittendorfer-Rutz, ${ }^{2}$ Fredrik Bondestam, ${ }^{3}$ Ida E H Madsen ${ }^{4}$}

${ }^{1}$ Stress Research Institute, Department of Psychology,

Stockholm University, 10691

Stockholm, Sweden

${ }^{2}$ Division of Insurance Medicine, Department of Clinical

Neuroscience, Karolinska Institutet, 17177 Stockholm,

Sweden

${ }^{3}$ Swedish Secretariat for Gender Research, Gothenburg University, 40530 Gothenburg, Sweden

${ }^{4}$ National Research Centre for the Working Environment, 2100 Copenhagen, Denmark

Correspondence to:

L Magnusson Hanson

linda.hanson@su.se

(ORCID 0000-0002-2908-1903) online only. To view please visit

the journal online.

Cite this as: BMJ2020;370:m2984 http://dx.doi.org/10.1136/bmj.m2984

Accepted: 13 July 2020
Additional material is published

\section{ABSTRACT}

OBJECTIVE

To analyse the relation between exposure to workplace sexual harassment and suicide, as well as suicide attempts.

DESIGN

Prospective cohort study.

SETTING

Sweden.

\section{PARTICIPANTS}

86451 men and women of working age in paid work across different occupations responded to a self-report questionnaire including exposure to work related sexual harassment between 1995 and 2013. The analytical sample included 85205 people with valid data on sexual harassment, follow-up time, and age.

\section{MAIN OUTCOME MEASURES}

Suicide and suicide attempts ascertained from administrative registers (mean follow-up time 13 years).

\section{RESULTS}

Among the people included in the respective analyses of suicide and suicide attempts, 125 (0.1\%) died from suicide and $816(1 \%)$ had a suicide attempt during follow-up (rate 0.1 and 0.8 cases per 1000 person years). Overall, 11 of 4095 participants exposed to workplace sexual harassment and 114 of 81110 unexposed participants committed suicide, and $61 / 4043$ exposed and 755/80513 unexposed participants had a record of suicide attempt. In Cox regression analyses adjusted for a range of sociodemographic characteristics, workplace sexual harassment was associated with an excess risk of both suicide (hazard ratio $2.82,95 \%$ confidence interval 1.49 to 5.34$)$ and suicide attempts $(1.59,1.21$ to 2.08), and risk estimates remained significantly increased after adjustment for baseline health and certain work characteristics. No obvious differences between men and women were found.

CONCLUSIONS

The results support the hypothesis that workplace sexual harassment is prospectively associated

\section{WHAT IS ALREADY KNOWN ON THIS TOPIC}

Sexual victimisation may lead to suicidal behaviour

However, no population based prospective studies on work related sexual harassment and suicide or suicide attempts have been conducted

\section{WHAT THIS STUDY ADDS}

This large population based cohort study of Swedish men and women indicates that workplace sexual harassment may be a risk factor for both suicide and suicide attempts with suicidal behaviour. This suggests that suicide prevention considering the social work environment may be useful. More research is, however, needed to determine causality, risk factors for workplace sexual harassment, and explanations for an association between work related sexual harassment and suicidal behaviour.

\section{Introduction}

Work related sexual harassment (referring to any unwanted and unwelcome acts or conduct of sexual nature, whether verbal or non-verbal, experienced as intimidating, hostile, degrading, humiliating, or offensive in circumstances related to work) ${ }^{12}$ has recently received a lot of attention thanks to the "Me Too" movement. This movement has put an emphasis on the widespread occurrence of sexual harassment, especially work related sexual harassment. Exact prevalences of work related sexual harassment in the working population are, however, difficult to estimate, and previous studies show large discrepancies. Whereas some reports have found that no less than $80 \%$ of all women and $30 \%$ of all men have experienced work related sexual harassment, other studies show much lower figures ranging from about $1 \%$ to $20 \%$, depending on representativeness, how sexual harassment was measured, and the time frame, as well as on cultural context. ${ }^{34}$

For organisations and the society, sexual harassment may involve substantial costs associated with turnover of personnel and absenteeism. ${ }^{5}{ }^{6}$ For individuals, sexual harassment may take a toll on self-esteem, life satisfaction, and employment opportunities. ${ }^{78}$ Work related sexual harassment may also be associated with a range of negative health outcomes. Previous literature has associated workplace sexual harassment with, for example, physical health symptoms, stress, posttraumatic stress, sickness absence, and particularly poorer mental health such as psychological distress, depression, and anxiety. ${ }^{25} 7910$ Sexual victimisation may also lead to suicidal behaviour, through an increased risk of psychiatric disease and psychosocial factors such as life events, problematic substance use/misuse, and risky lifestyle and behaviours, ${ }^{11}$ or through behavioural disinhibition, dysregulated mood, hopelessness, and entrapment. ${ }^{12}$ However, studies, especially prospective studies, on workplace sexual harassment and suicidal behaviours are lacking. Many studies have also been based on convenience samples or specific occupational groups. To our knowledge, no population based prospective studies on work related sexual harassment and suicidal behaviours have been reported. To rectify this, we did a prospective study 
on work related sexual harassment and suicide and suicide attempts in a large sample of Swedish men and women in paid work.

\section{Methods}

\section{Study population}

This study was based on data from the Swedish Work Environment Survey (SWES) 1995-2013. SWES is a biennial cross sectional survey, building on the Labour Force Survey. Every second year since 1989, a sample of between 10000 and 15000 people aged 16-74 years from the entire Swedish population are contacted as part of the Labour Force Survey. Those invited are selected by simple random sampling after stratification for county, sex, and age and are first interviewed by phone. Subsequently, the participants are asked to respond to self-completion questionnaires. A selected subsample aged 16-64 in paid work, largely representative of the Swedish workforce, are further asked to respond to self-completion questionnaires including a range of questions related to their work situation, as part of the SWES. Non-participation in Labour Force Survey and SWES varied between 13\% (1995) and 33\% (2013) in the initial interviews and between $23 \%$ (1995) and 51\% (2013) in the subsequent phone interviews and questionnaires. In total, 86451 participants responded to the SWES selfcompletion surveys in 1995-2013. After exclusion of people with reused personal identification numbers, missing data on workplace sexual harassment, and invalid data for the analyses on age at end of follow-up, the study sample included 85205 respondents.

\section{Sexual harassment}

Two questionnaire items about sexual harassment were used in this study, which were introduced as follows: "Sexual harassment refers to undesirable advances or offensive references to what is generally associated with sexual relations." The respondents were then asked to respond to: "Are you subjected to sexual harassment in your workplace from... 1) superiors or fellow workers? and 2) other people (eg, patients, clients, passengers, students)?" The questions were rated on a seven point Likert-type scale ranging from not at all during the previous 12 months to every day. We categorised people who reported that they were subjected to sexual harassment between once or twice during the previous 12 months and every day as being exposed to sexual harassment. We considered those reporting not being subjected to sexual harassment at all during the previous 12 months to be unexposed. We combined these two items into one variable for the main analyses, indicating any exposure to workplace sexual harassment during the previous 12 months. Because most respondents were exposed only once or twice during the previous 12 months, we did not do dose-response analyses.

\section{Suicide and suicide attempts}

We identified suicide and suicide attempts from the National Patient Register and Causes of Death
Register through linkage based on the Swedish personal identification number. The patient register includes both inpatient and outpatient data (from 2001). We defined people registered with an ICD10 (international classification of diseases, version 10) code of X60-X84 (self-inflicted harm) or Y10-Y34 (death with undetermined intent) as the underlying cause of death as cases of suicide. ${ }^{13-16}$ Likewise, we considered those registered with self-inflicted harm or harm with undetermined intent in the National Patient Register to be cases of attempted suicide. ${ }^{15}$ For ICD-8 and ICD-9, we used the corresponding codes E950959 and E980-989. For the analyses, we considered only incident suicide attempts occurring after response to SWES, excluding people with first attempts before participation in the survey (dating back to 1964 for inpatient data and 2001 based for outpatient data). We followed the respondents from the year of response to SWES questionnaires to the year of either first registered suicide attempt or suicide, death from another cause, emigration, or end of follow-up (31 December 2016).

\section{Statistical analyses}

We estimated the risk of suicide or suicide attempt by using proportional hazard regression analyses with age as the underlying time scale. We tested the proportional hazards assumption by using log-log plots and interaction between time and exposure, and we found no deviations from proportionality.

We fitted models assessing the relation both between workplace sexual harassment and risk of suicide and between workplace sexual harassment and risk of suicide attempts. All people with full information on exposure and outcome were included in the analyses of suicide. The main analyses of suicide attempts were carried out in a subsample with no previous suicide attempts (excluding 649 individuals from the total study sample) to make sure the exposure preceded the outcome, but we also did analyses alternatively adjusting for previous suicide attempts. The analyses were adjusted for sex, family type, country of birth, educational level, and income, as these types of factors have been found to be associated with workplace sexual harassment and risk factors for suicidal behaviour. $^{71718}$ Information about sex, age, family situation, country of birth, educational level, and income came from the longitudinal integration database for health insurance and labour market studies (LISA). We used educational level as a categorical variable with three categories ( $\leq 9$ years, $10-12$ years, and $\geq 13$ years). We categorised baseline family type as single, divorced, separated, or widowed without children; single, divorced, separated, or widowed with children; married or living with partner without children; or married or living with partner with children. We categorised country of birth as "Nordic countries," "other European countries," or "other continents." In additional analyses, we added poor mental health at baseline or history of poor mental health. Poor mental health was measured by baseline 
reports of being tired or listless ("During the past 3 months have you been tired and listless?") every day, which we used as an indicator of poor mental health, ${ }^{19}$ and/or a diagnosis of mental disorders as indicated by ICD-10 F01-99 or ICD-9/ICD-8 290-319 in the National Patient Register up to the year of survey response. ${ }^{20}$ In addition, we adjusted for baseline work characteristics including job demands and control, measured by indices for demands and control based on four items each scored from 0 to 4 . We also used an index for support at work measured with two separate questions about support from superiors and fellow workers, scored from 1 to 4, and for descriptive and/or analytical statistics considered workplace violence and bullying assessed by the following items: "Are you exposed to violence or threats of violence in your work?" and "Are you subjected to personal harassment by means of malicious words and actions from supervisors or colleagues?" We also ascertained severe somatic disease from the National Patient Register (including inpatient and outpatient data), including myocardial infarction, congestive heart failure, peripheral vascular disease, cerebrovascular disease, dementia, chronic pulmonary disease, rheumatological disease, peptic ulcer, mild liver disease, diabetes, hemiplegia or paraplegia, renal disease, any malignancy, moderate or severe liver disease, metastatic solid tumour, connective tissue disease, and HIV/AIDS. ${ }^{21}$ A variable indicating whether any of these illnesses had been diagnosed before or during the year of survey response was considered as a potential confounder. The data on previous or prevalent mental and somatic disorders dated back to 1994 for inpatient data and 2001 for outpatient data.

As adverse effects may differ for men and women, the analyses were also stratified according to sex, and an interaction term was included in some models, to assess whether the associations tended to differ between men and women. We additionally stratified the analyses by position of the exposed individuals, as workplace sexual harassment is also linked to hierarchical power relations and many previous studies have focused on subordinates. ${ }^{2} 6$ We categorised position as supervisor or subordinate. We regarded people with supervisory duties as supervisors and those reporting no supervisory duties as subordinates. Finally, we analysed sexual harassment from superiors or fellow workers versus sexual harassment from other people (for example, patients, clients, passengers, students) separately. We also did a sensitivity analysis with suicide and suicide attempts with self-inflicted harm only. We used SAS Statistical Software 9.4 for all analyses.

\section{Patient and public involvement}

No patients were involved in setting the research question or the outcome measures, nor were they involved in developing plans for recruitment, design, and implementation of the study. No patients were asked for advice on interpretation or writing up of results. However, part of the research and dissemination strategy at the Stress Research Institute is developed with patient and public involvement.

\section{Results}

Overall, 4.8\% (4095/85 205) of the included men and women reported workplace sexual harassment during the previous 12 months $-1.9 \%(774 / 40853)$ of all men and $7.5 \%(3321 / 44352)$ of all women. Those exposed to workplace sexual harassment tended to differ from the rest of the study population on several sociodemographic characteristics (table 1). Among the exposed participants, a higher proportion were women and single, divorced, or separated, and a slightly higher proportion were born outside Europe. Single or divorced men without children and men born outside Europe seemed to be disproportionally affected (supplementary table A). The exposed participants were also generally younger than the remainder of the study sample, and their income from work was lower, especially among women. Furthermore, a higher proportion of the exposed individuals were found to have non-supervisory duties and high strain jobs (characterised by high demands and low control), a pattern that was most obvious among women. A high proportion of the exposed participants concurrently reported exposure to violence or threats of violence and bullying from superiors or colleagues, which was especially true for men. Finally, a higher proportion of the exposed individuals were found to have poor mental health, among both men and women.

\section{Sexual harassment and risk of suicide}

We followed the study participants for a total of 1084512 person years (mean 13 years). In total, 125 (0.1\%) people died from suicide during follow-up (rate: 0.1 cases per 1000 person years), 11 (0.3\%) among people exposed to any workplace sexual harassment and $114(0.1 \%)$ among those unexposed to workplace sexual harassment.

In the Cox regression analyses (table 2), the hazard ratio for completed suicide was 2.23 (95\% confidence interval 1.19 to 4.16 ) for any workplace sexual harassment. The hazard ratio was considerably higher when we adjusted for sex. After adjustment for sex, birth country, family type, educational level, and income, the hazard ratio was 2.82 (1.49 to 5.34). This corresponded to a population attributable fraction of 0.06. Further adjustment for baseline mental health and working conditions resulted in a more than twofold higher risk of suicide among people exposed to workplace sexual harassment (hazard ratios 2.51 (1.29 to 4.90) and 2.47 (1.25 to 4.87), respectively). As history of somatic disease did not differ notably between exposed and unexposed participants, we made no adjustment for somatic disease.

We noted excess risk estimates in both men and women (table 2), and we found no statistically significant interaction between workplace sexual harassment and sex. Similarly, we detected no statistically significant interaction between workplace sexual harassment and position (superior versus 


\begin{tabular}{|c|c|c|c|}
\hline Characteristic & All $(n=85205)$ & $\begin{array}{l}\text { Not exposed to workplace sexual } \\
\text { harassment }(n=81110)\end{array}$ & $\begin{array}{l}\text { Exposed to workplace sexual } \\
\text { harassment }(n=4095)\end{array}$ \\
\hline \multicolumn{4}{|l|}{ Sex: } \\
\hline Male & $40853(48)$ & $40079(49)$ & 774 (19) \\
\hline Female & $44352(52)$ & $41031(51)$ & $3321(81)$ \\
\hline Mean (SD) age, years & $43(11.9)$ & $43(11.8)$ & $37(11.5)$ \\
\hline Birth country: & $(n=85198)$ & $(n=81103)$ & \\
\hline Nordic countries & $81288(95)$ & $77415(95)$ & $3873(95)$ \\
\hline Other European countries & $2280(3)$ & $2170(3)$ & $110(3)$ \\
\hline Elsewhere & $1630(2)$ & $1518(2)$ & $112(3)$ \\
\hline \multicolumn{4}{|l|}{ Family situation: } \\
\hline Married/living with partner with children & $39682(47)$ & $38007(47)$ & $1675(41)$ \\
\hline Married/living with partner without children & $15451(18)$ & $15066(19)$ & $385(9)$ \\
\hline Single/divorced/separated/widowed with children & $6522(8)$ & $6039(7)$ & $483(12)$ \\
\hline Single/divorced/separated/widowed without children & $23550(28)$ & $21998(27)$ & $1552(38)$ \\
\hline Education: & $(n=83449)$ & $(n=80240)$ & $(n=4005)$ \\
\hline Primary and lower secondary education & $12861(15)$ & $12470(16)$ & $391(10)$ \\
\hline Upper secondary education & $41295(49)$ & $39186(49)$ & $2109(53)$ \\
\hline University education & $29293(35)$ & $28584(36)$ & $1505(38)$ \\
\hline Mean (SD) income from work, SEK & $2467210(1519490)$ & $24875500(1533790)$ & $2064420(1128590)$ \\
\hline Supervisory duties: & $(n=84919)$ & $(\mathrm{n}=80835)$ & $(n=4084)$ \\
\hline No & $59375(70)$ & $56454(70)$ & $2921(71)$ \\
\hline Yes & $25544(30)$ & $24381(30)$ & $1163(28)$ \\
\hline Mean (SD) job demands, scale 0-4 & $1.7(1.3)$ & $1.7(1.3)$ & $2.1(1.3)$ \\
\hline Mean (SD) job control, scale 0-4 & $2.5(1.3)$ & $2.5(1.3)$ & $1.9(1.3)$ \\
\hline Mean (SD) social support, scale 1-4 & $1.6(0.9)$ & $1.6(0.9)$ & $1.7(0.9)$ \\
\hline Exposure to workplace violence: & $(n=84951)$ & $(n=80883)$ & $(n=4068)$ \\
\hline No & $73395(86)$ & $71415(88)$ & $1980(49)$ \\
\hline Yes & $11556(14)$ & $9468(12)$ & $2088(51)$ \\
\hline Exposure to workplace bullying: & $(n=85002)$ & $(n=80929)$ & $(n=4073)$ \\
\hline No & $77773(91)$ & $74556(92)$ & $3217(79)$ \\
\hline Yes & $7229(9)$ & $6373(8)$ & $856(21)$ \\
\hline Baseline poor mental health: & $(n=84003)$ & $(n=79962)$ & $(n=4041)$ \\
\hline No & $79930(95)$ & $76267(95)$ & $3663(91)$ \\
\hline Yes & $4073(5)$ & $3695(5)$ & $378(9)$ \\
\hline \multicolumn{4}{|l|}{ Baseline somatic disease: } \\
\hline No & $71919(84)$ & $68411(84)$ & $3508(86)$ \\
\hline Yes & $13286(16)$ & $12699(16)$ & $587(14)$ \\
\hline \multicolumn{4}{|l|}{ Suicide: } \\
\hline No & $85080(100)$ & $80996(100)$ & $4084(100)$ \\
\hline Yes & $125(0)$ & $114(0)$ & $11(0)$ \\
\hline \multicolumn{4}{|l|}{ Suicide attempt: } \\
\hline No & $83740(98)$ & $79758(98)$ & $3982(97)$ \\
\hline Yes & $1465(2)$ & $1352(2)$ & $113(3)$ \\
\hline
\end{tabular}

subordinate), although the risk of suicide seemed to be more marked among subordinates (table 3 ), which may be at least partly due to a higher number of subordinates $(n=59375 v 25544)$ and prevalence of sexual harassment among subordinates (4.9\% (2921 exposed) $v 4.6 \%$ (1163).

In the total sample, $1.5 \%(1253 / 85189)$ were exposed to sexual harassment from superiors or fellow workers and 3.8\% (3247/85195) were exposed to sexual harassment from other people (for example, patients, clients, passengers, students). When we looked at the association between workplace sexual harassment perpetrated by superiors or fellow workers and suicide (table 4), the risk estimate was above 1 but not statistically significant, which may be at least partly due to low prevalence of exposure and number of suicide cases in the exposed group $(n=2)$. The corresponding analyses on sexual harassment by other people such as clients or customers indicated an increased risk of suicide (adjusted hazard ratio 3.32, 1.71 to 6.48 ). The sensitivity analyses on risk of suicide excluding cases with undetermined intent were similar to the main findings (supplementary tables B-D).

\section{Workplace sexual harassment and risk of suicide attempts}

Among participants without a previous suicide attempt ( $n=84556), 816$ (1\%) were found to have a suicide attempt during follow-up (1072312 person years; rate 0.8 , mean follow-up time 13 years)-61/4043 (2\%) among people exposed to any workplace sexual harassment and 755/80513 (1\%) among those unexposed to workplace sexual harassment.

As for suicide, any workplace sexual harassment was also associated with an increased risk of suicide attempt (unadjusted hazard ratio 1.54, 1.19 to 2.01), and the hazard ratio remained similar after adjustment for sociodemographic characteristics $(1.59,1.21$ to 


\begin{tabular}{|c|c|c|c|c|c|c|c|c|c|}
\hline & \multicolumn{3}{|c|}{ All } & \multicolumn{3}{|c|}{ Men } & \multicolumn{3}{|c|}{ Women } \\
\hline & $\begin{array}{l}\text { No with } \\
\text { valid data }\end{array}$ & $\begin{array}{l}\text { No of } \\
\text { cases }\end{array}$ & $\mathrm{HR}(95 \% \mathrm{Cl})$ & $\begin{array}{l}\text { No with } \\
\text { valid data }\end{array}$ & $\begin{array}{l}\text { No of } \\
\text { cases }\end{array}$ & $\mathrm{HR}(95 \% \mathrm{Cl})$ & $\begin{array}{l}\text { No with } \\
\text { valid data }\end{array}$ & $\begin{array}{l}\text { No of } \\
\text { cases }\end{array}$ & $\mathrm{HR}(95 \% \mathrm{Cl})$ \\
\hline \multicolumn{10}{|l|}{ Suicide } \\
\hline Model $0^{\star}$ & 85205 & 125 & $2.23(1.19$ to 4.16$)$ & 40853 & 87 & 2.99 (1.09 to 8.18) & 44353 & 38 & $3.20(1.39$ to 7.33$)$ \\
\hline Model 1† & 84238 & 124 & $2.82(1.49$ to 5.34$)$ & 40421 & 86 & $2.62(0.95$ to 7.19$)$ & 43817 & 38 & 2.94 (1.28 to 6.76$)$ \\
\hline Model 2 $\ddagger$ & 83048 & 121 & 2.51 (1.29 to 4.90$)$ & 39877 & 84 & $2.62(0.95$ to 7.22$)$ & 43171 & 37 & $2.39(0.98$ to 5.80$)$ \\
\hline Model 3§ & 82860 & 121 & $2.47(1.25$ to 4.87$)$ & 39794 & 84 & $2.60(0.92$ to 7.34$)$ & 43066 & 37 & $2.25(0.91$ to 5.56$)$ \\
\hline \multicolumn{10}{|c|}{ Suicide attempts } \\
\hline Model $0^{\star}$ & 84556 & 816 & 1.54 (1.19 to 2.01$)$ & 40540 & 397 & $1.79(1.03$ to 3.11$)$ & 44016 & 419 & 1.49 (1.10 to 2.02$)$ \\
\hline Model 1† & 83600 & 799 & 1.59 (1.21 to 2.08$)$ & 40111 & 391 & $1.80(1.03$ to 3.13$)$ & 43489 & 408 & 1.49 (1.09 to 2.02$)$ \\
\hline Model $2 \ddagger$ & 82419 & 786 & 1.55 (1.18 to 2.04$)$ & 39570 & 385 & $1.78(1.02$ to 3.11$)$ & 42849 & 401 & 1.44 (1.06 to 1.98$)$ \\
\hline Model $3 \S$ & 82233 & 785 & 1.56 (1.18 to 2.05$)$ & 39488 & 384 & 1.77 (1.01 to 3.12) & 42745 & 401 & $1.47(1.07$ to 2.02$)$ \\
\hline
\end{tabular}

2.08) (table 2). This corresponded to a population attributable fraction of 0.03. Moreover, further adjustment for baseline poor mental and physical health, as well as working conditions, did not markedly attenuate the risk estimates, and the risk estimates did not differ considerably by sex or position (supervisor versus subordinate). Analyses alternatively adjusting for previous suicide attempts resulted in lower hazard ratios. A model adjusting for previous suicide attempt, sex, birth country, family type, educational level, and income showed a hazard ratio of 1.25 (1.01 to 1.49) and a fully adjusted model a hazard ratio of $1.23(1.00$ to 1.52 ).

When we looked at the association between workplace sexual harassment perpetrated by superiors or fellow workers and suicide attempts, the analyses showed a statistically significant association when the models were adjusted for sex, birth country, family type, educational level, and income (table 4). The corresponding analyses on sexual harassment by other people such as clients or customers also indicated an increased risk of suicide attempts (adjusted hazard ratio $1.74,1.30$ to 2.31 ).

In sensitivity analyses excluding cases with undetermined intent, the estimates of association between workplace sexual harassment and suicide attempts were stronger (supplementary tables B-D). The hazard ratio for any exposure to sexual harassment was 2.22 (1.54 to 3.20) in the sensitivity analysis adjusted for sociodemographic characteristics.

\section{Discussion}

This population based cohort study of Swedish men and women showed an association between workplace sexual harassment and both suicide and suicide attempts.

\section{Strengths and limitations of study}

This study has several major strengths such as a prospective design and relatively large sample approximately representative of the Swedish working population. Prospective cohort studies typically provide stronger evidence than other observational studies. However, the study also has limitations, including a risk that sexual harassment is underreported. In this study, we based our variables on only one single question, and lower rates of exposure to sexual harassment tend to be found with one question than with different questions about particular forms of behaviour. ${ }^{3}{ }^{4}$ However, a definition was provided in this study, which may have increased the validity of the data. Underreporting may have contributed to an underestimation of associations due to nondifferential misclassification. On the other hand, the forms of sexual harassment may vary widely, with some people experiencing light forms such as remarks whereas others are exposed to severe forms such as rape. When asked explicitly about sexual harassment, many respondents seem to consider only severe types of sexual harassment. ${ }^{3}$ This may be an explanation for the relatively strong associations in this study. No assessment of type and severity was available, however, and we cannot exclude the possibility that the respondents only witnessed sexual harassment at their workplace. When comparing effects on wellbeing, however, some authors have found comparable effects of less intensive but frequent experiences such as gender harassment and more intense but infrequent experiences such as sexual coercion and unwanted sexual attention. ${ }^{22}$ We also analysed sexual harassment from superiors or fellow workers and from others separately and found that sexual harassment from others was more strongly associated with suicide than was sexual harassment from superiors and fellow workers. This finding is surprising in light of previous Danish analyses, which found that depressive symptoms were more strongly associated with sexual harassment from superiors and colleagues than with sexual harassment from customers or clients. ${ }^{23}$ Although the findings of our study on this point should be interpreted carefully in light of the limited power, further research into how and why the consequences of sexual harassment may differ depending on the relation to the harasser may be justified.

With respect to the ascertainment of suicide and suicide attempts, the Swedish registers generally have 


\begin{tabular}{|c|c|c|c|c|c|c|}
\hline & \multicolumn{3}{|c|}{ Supervisor* } & \multicolumn{3}{|c|}{ Subordinate* } \\
\hline \multicolumn{7}{|l|}{ Suicide } \\
\hline Model O† & 25544 & 35 & $1.60(0.38$ to 6.70$)$ & 59375 & 90 & $2.46(1.23$ to 4.94$)$ \\
\hline Model 1f & 25388 & 35 & $1.94(0.45$ to 8.42$)$ & 58564 & 89 & 3.18 (1.56 to 6.47$)$ \\
\hline Model 39 & 25035 & 33 & $0.95(0.12$ to 7.30$)$ & 57548 & 88 & $3.05(1.47$ to 6.33$)$ \\
\hline \multicolumn{7}{|c|}{ Suicide attempts } \\
\hline Model O† & 25365 & 221 & 1.77 (1.08 to 2.88$)$ & 58908 & 593 & $1.43(1.04$ to 1.96$)$ \\
\hline Model 1‡ & 25210 & 219 & 1.98 (1.20 to 3.28$)$ & 58107 & 578 & $1.42(1.03$ to 1.97$)$ \\
\hline Model $2 \S$ & 24912 & 217 & 1.97 (1.19 to 3.26$)$ & 57233 & 567 & 1.38 (0.99 to 1.92$)$ \\
\hline
\end{tabular}

high completeness and validity. ${ }^{24}$ High agreement for suicide between death certificates and other sources of information such as forensic reports, police reports, and toxicological and histological data has also been found. ${ }^{25}$ However, the data are likely to cover the most severe cases. Moreover, the number of false positives may have been increased by the inclusion of deaths or diagnoses with undermined intent. ${ }^{26}$ This has on the other hand been found to reduce under-detection and incorrect coding, as well as spatial and secular trends in detection and classification of suicide, ${ }^{13}$ and additional analyses excluding cases with undetermined intent strengthened the main findings. In addition, the assessment of suicide attempts may be more challenging, with a higher risk for underascertainment owing to absence of recorded clinical care. Non-differential misclassification of the outcome may have contributed to attenuation of the results.

The analyses were adjusted for some potential confounding factors including demographic characteristics and other working conditions, which did not seem to explain the associations between workplace sexual harassment and suicide as well as suicide attempts. However, unmeasured factors such as evening/night work and precarious employment are other possible confounders of the associations of interest. People who are more vulnerable to suicidal behaviours might be more likely to be employed in occupations with increased risk of harassment. We also considered records of pre-existing mental and physical disease, which included various psychiatric disorders, substance misuse, and personality disorders. This strengthens the findings but may on the other hand lead to an underestimation of the association if poor mental health and substance misuse act as mediators of the relation between workplace sexual harassment and suicidal behaviour. However, we cannot rule out residual confounding and confounding from other factors, although only very strong confounding could completely explain the results. Pre-existing poor mental health might partly explain the results of the study, as people with pre-existing poor mental health are more likely to perceive themselves as harassed and more likely to be suicidal. We were also unable to account for certain personality traits such as neuroticism, ${ }^{18}$ genetic factors, childhood adversities, and social isolation, which could act as confounders for the association between workplace sexual harassment and suicide.

Also, the response rate in SWES has decreased over time. The non-responders to SWES tend to consist of a higher proportion of young people, people with low education and low income, and immigrants. This attrition may have affected the estimates of prevalence and risk, and decreases the generalisability of the results. A major strength of this study on the other hand is that we had practically no loss to follow-up and long follow-up time. ${ }^{24}$

\section{Strengths and weaknesses in relation to other studies}

To our knowledge, this is the first study to indicate that workplace sexual harassment increases the risk of suicidal behaviour in the general working population. We are aware of only a few previous studies on this topic. For example, Griffith (2019) showed an association between workplace sexual harassment and suicide attempts in the US, ${ }^{27}$ and Jin et al (2018) showed an association with self-harm in Taiwan. ${ }^{28}$ However, both of these studies included military personnel only, used a cross sectional design, and studied only suicide attempts and not suicide. The cross sectional design means that their results may have been influenced by recall bias and common method bias. In this study, we instead used a prospective design with exposure assessed by questionnaire but suicide and suicide attempts ascertained from administrative registers. This excludes dependent recall bias and reduces the risk of common method variance. The study is also based on a large sample representative of different sectors and occupations in Sweden, with much greater power than many previous studies on the topic.

Nevertheless, our results are in line with those of the few previous studies on workplace sexual harassment 


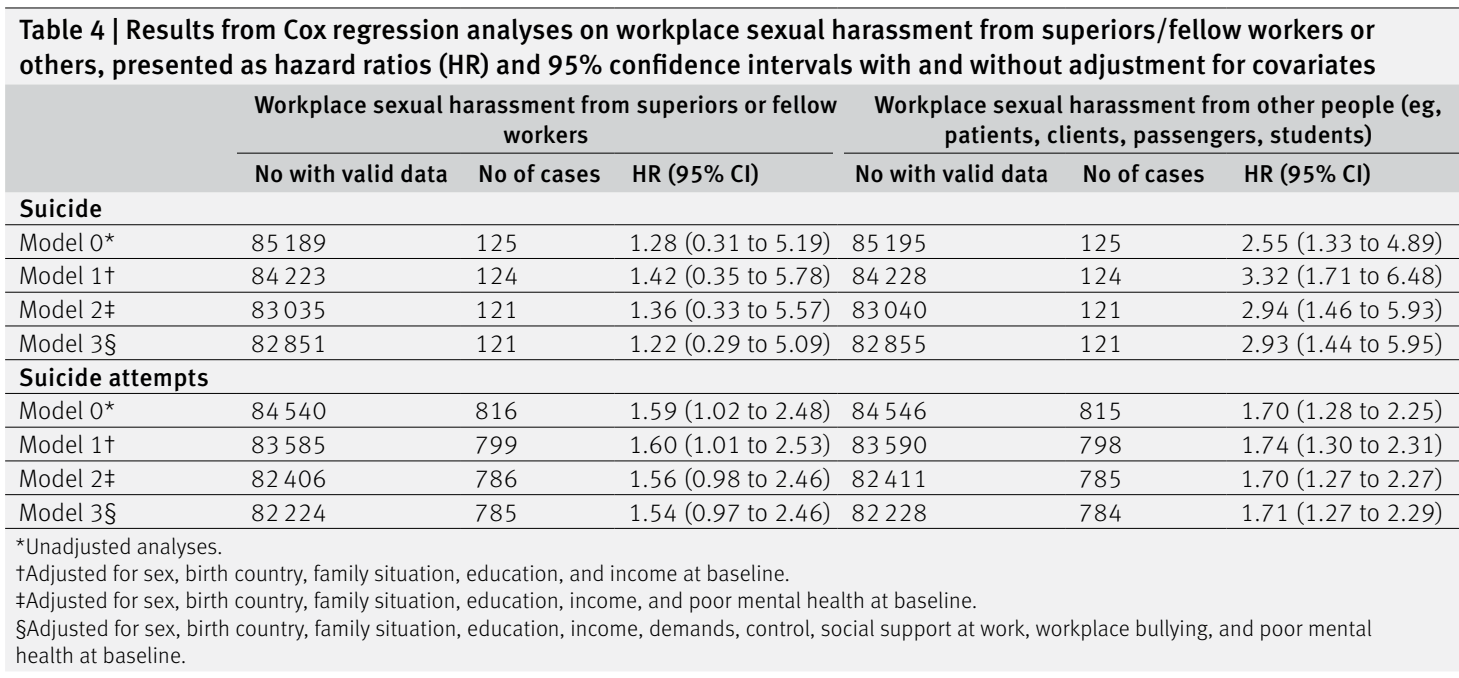

and with results on childhood sexual victimisation and suicide attempts. ${ }^{29}$ Studies show that people exposed to sexual abuse and repetitive abuse in childhood are particularly vulnerable to suicidality in adulthood. ${ }^{30}$ In line with the stress diathesis model, distal factors such genetics and childhood adversity may have contributed to a diathesis (a predisposition) to suicidal behaviour, and an increased risk of suicidal behaviour could be explained by this diathesis together with proximal risk factors such as exposure to sexual harassment. $^{31}$ An interaction between a variety of biological, clinical, psychological, social, cultural, and environmental factors can affect the risk of suicide; most commonly, several risk factors act cumulatively to increase an individual's vulnerability to suicidal behaviour. ${ }^{12} 14$ Early life adversities such as sexual or physical abuse have been connected to a range of emotional and behavioural changes, related cognitive deficits, and epigenetic changes. This seems to increase the risk of development of pathological traits, emotional dysregulation, altered brain structure, and impaired executive function, which may increase the vulnerability to suicidal behaviour. ${ }^{12}$ Childhood abuse has for instance been found to be strongly associated with a diagnosis of post-traumatic stress disorder, ${ }^{32}$ involving, for example, extreme fear, helplessness, persistent arousal, and anxiety, which are risk factors for suicidality. Workplace sexual harassment has also been associated with post-traumatic stress disorder, ${ }^{7}$ and it may be associated with similar emotional and behavioural changes, cognitive deficits, and epigenetic changes. Workplace sexual harassment is likely to be associated with other stress responses and could lead to behavioural risks such as eating disorders and drug and alcohol misuse, ${ }^{7}$ as well as depressive symptoms, ${ }^{9}$ ${ }^{23}$ which may in turn increase the risk of suicide or suicide attempts.

\section{Conclusions and policy implications}

All in all, this study supports a prospective association between workplace sexual harassment and suicidal behaviour. Workplace sexual harassment may thus represent an important risk factor for suicidal behaviour. This suggests that workplace interventions focusing on the social work environment and behaviours could contribute to a decreased burden of suicide. More research is, however, needed to determine causality and on risk factors for workplace sexual harassment and mechanisms explaining the association between work related sexual harassment and suicidal behaviour.

Contributors: LLMH conceived and designed the study, did the statistical analysis, and drafted the manuscript. All authors provided critical input to the design and the analysis and interpretation of the data and revised the manuscript critically. The corresponding author attests that all listed authors meet authorship criteria and that no others meeting the criteria have been omitted. LLMH is the guarantor. Funding: This study was supported by the Swedish Research Council for Health, Working Life and Welfare (\#2019-01318). Data collection and management were also supported by the Swedish Research Council (\#2018-00544). The funders had no role in considering the study design or in the collection, analysis, or interpretation of data; writing of the report; or the decision to submit the article for publication.

Competing interests: All authors have completed the ICMJE uniform disclosure form at www.icmje.org/coi disclosure.pdf and declare: LLMH received grants from the Swedish Research Council for Health, Working Life and Welfare during the conduct of the study; no financial relationships with any organisations that might have an interest in the submitted work in the previous three years; no other relationships or activities that could appear to have influenced the submitted work. Ethical approval: This study has been approved by the Regional Research Ethics Board in Stockholm (document numbers: 2012/373 31/5, 2013/2173-32, 2015/2187-32, 2015/2298-32, and 2017/2535-32). Participants in the Swedish Work Environment Survey received written information on the survey, and return of the survey indicated informed consent.

Data sharing: Relevant data for research purposes from the Swedish Work Environment Surveys and the Longitudinal Integrated Database for Health Insurance and Labour Market Studies (LISA) can be requested from Statistics Sweden. Relevant data for research from the National Patient Register and Causes of Death Register can be requested from the National Board of Health and Welfare.

Transparency: The lead author (the manuscript's guarantor) affirms that the manuscript is an honest, accurate, and transparent account of the study being reported; that no important aspects of the study have been omitted; and that any discrepancies from the study as planned (and, if relevant, registered) have been explained.

Dissemination to participants and related patient and public communities: There are no plans to disseminate the results of the research directly to the study participants. Dissemination to the 
population, in general, will be through the Stockholm University website, seminars/conferences, and the media.

This is an Open Access article distributed in accordance with the Creative Commons Attribution Non Commercial (CC BY-NC 4.0) license, which permits others to distribute, remix, adapt, build upon this work non-commercially, and license their derivative works on different terms, provided the original work is properly cited and the use is noncommercial. See: http://creativecommons.org/licenses/by-nc/4.0/.

$1 \quad$ Fitzgerald L, Swan S, Magley V. But was it really sexual harassment? Legal, behavioral and psychological definitions of the workplace victimization of women. In: O'Donohue W, ed. Sexual Harassment: Theory, Research and Treatment. Allyn \& Bacon, 1997: 5-28.

2 McDonald P. Workplace Sexual Harassment 30 Years on: A Review of the Literature. Int J Manag Rev 2012;14:1-17. doi:10.1111/j.1468$2370.2011 .00300 x$

3 Timmerman G, Bajema C. Incidence and methodology in sexual harassment research in Northwest Europe. Womens Stud Int Forum 1999;22:673-81. doi:10.1016/S0277-5395(99)00076-X

4 Nielsen MB, Bjorkelo B, Notelaers G, Einarsen S. Sexual Harassment: Prevalence, Outcomes, and Gender Differences Assessed by Three Different Estimation Methods. J Aggress Maltreat Trauma 2010:19:252-74 doi:10.1080/10926771003705056

5 Willness CR, Steel P, Lee K. A meta-analysis of the antecedents and consequences of workplace sexual harassment. Person Psychol 2007;60:127-62. doi:10.1111/j.17446570.2007.00067.x

6 Quick JC, McFadyen MA. Sexual harassment: Have we made any progress?] Occup Health Psychol 2017;22:286-98. doi:10.1037/ ocp0000054

7 Cortina LM, Berdahl JL. Sexual harassment in organizations: A decade of research in review. In: Barling J, Cooper CL, eds. Micro Approaches. SAGE Publications, 2008: 469-97. (The SAGE Handbook of Organizational Behavior1.) doi:10.4135/9781849200448.n26

8 Fitzgerald LF, Drasgow F, Hulin CL, Gelfand MJ, Magley VJ. Antecedents and consequences of sexual harassment in organizations: a test of an integrated model. J Appl Psychol 1997;82:578-89. doi:10.1037/0021-9010.82.4.578

9 Nielsen MB, Einarsen S. Prospective relationships between workplace sexual harassment and psychological distress. Occup Med (Lond) 2012;62:226-8. doi:10.1093/occmed/kqs010

10 Hogh A, Conway PM, Clausen T, Madsen IE, Burr H. Unwanted sexual attention at work and long-term sickness absence: a follow-up register-based study. BMC Public Health 2016;16:678. doi:10.1186/ s12889-016-3336-y

11 Ullman SE. Sexual assault victimization and suicidal behavior in women: a review of the literature. Aggress Violent Behav 2004;9:331-51. doi:10.1016/S1359-1789(03)00019-3

12 Turecki G, Brent DA, Gunnell D, et al. Suicide and suicide risk. Nat Rev Dis Primers 2019;5:74. doi:10.1038/s41572-019-0121-0

13 Linsley KR, Schapira K, Kelly TP. Open verdict v. suicide - importance to research. Br J Psychiatry 2001;178:465-8. doi:10.1192/ bjp.178.5.465

14 World Health Organization. Preventing suicide: a global imperative. World Health Organization, 2014.

15 Randall JR, Roos LL, Lix LM, Katz LY, Bolton JM. Emergency department and inpatient coding for self-harm and suicide attempts: Validation using clinician assessment data. Int J Methods Psychiatr Res 2017;26:e1559. doi:10.1002/mpr.1559

16 Naghavi MGlobal Burden of Disease Self-Harm Collaborators. Global, regional, and national burden of suicide mortality 1990 to 2016: systematic analysis for the Global Burden of Disease Study 2016. BMJ 2019;364:194. doi:10.1136/bmj.194

17 Turecki G, Brent DA. Suicide and suicidal behaviour. Lancet 2016;387:1227-39. doi:10.1016/S0140-6736(15)00234-

18 Batty GD, Kivimäki M, Bell S, et al. Psychosocial characteristics as potential predictors of suicide in adults: an overview of the evidence with new results from prospective cohort studies. Transl Psychiatry 2018;8:22. doi:10.1038/s41398-017-0072-8

19 Bech P. Depressed mood as a core symptom of depression. Medicographia 2008;94:9-13

20 Hvidberg MF, Johnsen SP, Glümer C, Petersen KD, Olesen AV, Ehlers L. Catalog of 199 register-based definitions of chronic conditions. Scand J Public Health 2016;44:462-79. doi:10.1177/1403494816641553

21 Quan H, Sundararajan V, Halfon P, et al. Coding algorithms for defining comorbidities in ICD-9-CM and ICD-10 administrative data. Med Care 2005;43:1130-9. doi:10.1097/01. mlr.0000182534.19832.83

22 Sojo V, Wood R, Genat A. Harmful Workplace Experiences and Women's Occupational Well-Being: A Meta-Analysis. Psychol Women Q 2016;40:10-40. doi:10.1177/0361684315599346

23 Friborg MK, Hansen JV, Aldrich PT, et al. Workplace sexual harassment and depressive symptoms: a cross-sectional multilevel analysis comparing harassment from clients or customers to harassment from other employees amongst 7603 Danish employees from 1041 organizations. BMC Public Health 2017;17:675. doi:10.1186/ s12889-017-4669-x

24 Erlangsen A, Qin P, Mittendorfer-Rutz E. Studies of Suicidal Behavior Using National Registers. Crisis 2018;39:153-8. doi:10.1027/02275910/a000552

25 Allebeck P, Allgulander C, Henningsohn L, Jakobsson SW. Causes of death in a cohort of 50,465 young men--validity of recorded suicide as underlying cause of death. Scand / Soc Med 1991;19:242-7. doi:10.1177/140349489101900405

26 Swain RS, Taylor LG, Braver ER, Liu W, Pinheiro SP, Mosholder AD. A systematic review of validated suicide outcome classification in observational studies. Int J Epidemiol 2019;48:1636-49. doi:10.1093/ije/dyz038

27 Griffith !. The Sexual Harassment-Suicide Connection in the U.S. Military: Contextual Effects of Hostile Work Environment and Trusted Unit Leaders. Suicide Life Threat Behav 2019;49:41-53. doi:10.1111/sltb.12401

28 Jin HT, Lin YC, Strong C. Job stress, sexual harassment, self-harm behavior, and suicidal ideation among military personnel in Taiwan. Soc Health Behav 2018;1:11-5.

29 Zatti C, Rosa V, Barros A, et al. Childhood trauma and suicide attempt: A meta-analysis of longitudinal studies from the last decade. Psychiatry Res 2017;256:353-8. doi:10.1016/j. psychres.2017.06.082

30 Angelakis I, Gillespie EL, Panagioti M. Childhood maltreatment and adult suicidality: a comprehensive systematic review with meta-analysis. Psychol Med 2019;49:1057-78. doi:10.1017/ S0033291718003823

31 Wasserman D, ed. Suicide: An unnecessary death. Oxford University Press, 2016. doi:10.1093/med/9780198717393.001.0001

32 Hailes HP, Yu R, Danese A, Fazel S. Long-term outcomes of childhood sexual abuse: an umbrella review. Lancet Psychiatry 2019;6:830-9. doi:10.1016/S2215-0366(19)30286-X

Web appendix: Supplementary tables 